\title{
Usability is the Best Policy: Public Policy and the Lived Experience of Transport Systems in London
}

\author{
Philip Inglesant \\ Department of Computer Science \\ University College London \\ Gower Street, London WC1E 6BT \\ +44 (0) 2076793039 \\ P.Inglesant@cs.ucl.ac.uk
}

\author{
M. Angela Sasse \\ Department of Computer Science \\ University College London \\ Gower Street, London WC1E 6BT \\ +44 (0) 2076797212
}

A.Sasse@cs.ucl.ac.uk

\begin{abstract}
This paper explores the relations between public policy and usability in lived experience, drawing on 3 case studies in one important area of urban policy, transport. For these studies, discourse from interviews and focus groups with a total of 120 participants, and a written corpus of over 80 documents, were collected and analyzed, together with interviews with 25 key staff and observations of user interactions both in the laboratory and in situ. The resulting rich dataset presents a new perspective on e-government systems in use. The results show that usability must be prioritised at the policy design stage; it cannot be left to implementation. Failure to do so is experienced by users in systems which fail to work together to meet their needs. Negative experiences, in turn, may lead to loss of trust and legitimacy, and detract from public value and community well-being. These findings, therefore, provide lessons from HCI insights for both public policy-makers and implementers of e-government systems. The paper concludes by suggesting some HCI methods for pre-venting usability problems in e-government systems, by involving users in design in order to understand their lived experiences around the ecology of the systems.
\end{abstract}

\section{Categories and Subject Descriptors}

H.5.2 [Information Interfaces and Presentation (e.g., HCI)]: User Interfaces - user-centered design; C.3 [Special-Purpose and Application-Based Systems]: Smartcards.

\section{General Terms}

Design, Human Factors, Theory.

\section{Keywords}

Ubiquitous computing, embodied interaction, public policy, e-government, lived experience, usability, design.

\section{INTRODUCTION}

The use of computers by government is not new. However, 'computers' are changing: the Internet, mobile communications, and computer power incorporated into smaller and cheaper personal devices, are coming together, so that computers are more and more integrated into daily experience [45]. So, increasingly, e-Government meets the public not only in increased efficiency and better information for existing government services, but in new services provided in new ways.

With these extensions of computer power comes a widening of the boundaries for Human-computer interaction research. Computers are now everywhere, often unseen. People encounter them in many different ways in different contexts of use, not only in the workplace; interactions with computers are no longer restricted to the keyboard, mouse, and monitor.

In software development, the role of design in creating a positive user experience has been recognised at least since Kapor [27], in the early 1990s, put forward the case for software design distinct from user interface design and from software engineering, even if this has not always been honoured in practice. Yet in public policy, design starts long before the implementation of systems, with decisions made to balance the interests of divergent stakeholders [3].

\subsection{Why this Matters in e-Government}

In the private sector, services must be appealing to customers as well as free of basic usability problems to succeed. But quality services have additional urgency in e-government, for two reasons. Firstly, good public services are important to strengthen political legitimacy as sources of public value [28]. Secondly, government provides or enables public services in pursuit of desired policy outcomes. These outcomes could include, for example, the encouragement of behaviour change (e.g., to use public transport, rather than the car). But beyond these immediate outcomes are wider goals such as social inclusion, environmental sustainability, and community wellbeing; this has implications for the evaluation of systems in support of public policy [20].

Poor usability might be expected to reduce take-up of e-government initiatives. Take-up is important if the larger public policy aim is to free resources, perhaps towards the provision of better services in other ways. Margetts and Dunleavy [31] examine demand-side barriers to e-government. In usability terms, innovations must be capable of domestication; they must fit into everyday, personal routines. The transaction costs, the effort and time required in learning new ways of doing things, are a strong initial barrier to adoption; it has been repeatedly shown that even small up-front costs deter people from making a change, even if this would lead to a saving in the long run. 
It is well-established, however, that usability is not the only determinant of take-up [10]. There must be clear benefits from using electronic rather than traditional channels [31]; and this is in the context in which a more consumerist public has high expectations of quality, influenced by their experiences of private-sector services [28].

Government, like the private sector, could give financial incentives (or impose financial dis-incentives) to encourage behaviour change by citizens, or simply to increase take-up, but government, unlike commerce, can also draw on its authority [23] to use more coercive measures. However, deeper behaviour change can only be on the basis of intrinsic motivation, based on factors such as interest and enjoyment [9].

Usability is therefore an important, yet often under-considered, aspect of e-government. Citizens' satisfaction with public services is an essential contribution to public value in its own right; but as well as this, in achieving policy outcomes, trust, legitimacy, and co-operation are preferable to an antagonistic relation between citizen and government.

Unfortunately, as the findings in this paper illustrate, usability is currently often overlooked in public policy design - there is a misconception of usability as 'something the system implementer will take care of'. But the origins of usability problems may lie with public policy decisions which cannot be overcome at the implementation stage.

\subsection{Meeting This Need in HCI Research}

The findings of this paper are drawn from 3 case studies of e-government in a large urban area (London) in an application area (transport) which is widely considered to be one of the most pressing concerns of urban government. Transport touches the daily lives of most Londoners and visitors. At the same time, use of transport is outside traditional locations of HCI concern, being inherently mobile and outside the home or workplace, and so extends the HCI understanding of usability into the lived experiences of service users.

These issues are addressed in this paper as follows. Section 2 builds on existing research in interactions between people and computers to develop such an understanding. Based on this framework, usability issues in each of the case studies are identified, in Section 3; common themes which give coherence to these issues are joined together in Section 4.

This is the basis on which, in Section 5, the implications of these issues for public policy are analysed. It is argued that the insights of HCI research have lessons for policy-makers, not only in the implementation, but in the making of public policy at all stages. Beyond the interface, this implies the need to understand the real-world, situated actions of service users. The paper ends with some suggestions from the HCI tradition for carrying this out in practice.

\section{BACKGROUND}

In systems design, there is no longer the lack of consideration for usability; the former secret shame [27] is now seen as a crucial component, even by the engineering mainstream. Yet a usability engineering approach can fail to see the complexity of the social and situational context of interaction [11].

Intrinsic motivation and a relation of public trust and co-operation in government suggest the need for e-government systems to emphasise softer, hard-to-measure aspects of usability, beyond the absence of problems, to pleasure and even enjoyment. E-Government should meet the needs of users, not the other way round; this implies the need for policy-making which is citizen-centred, in the sense that the citizens situated needs are placed foremost and evaluated at all stages of policy design.

\subsection{Usability Beyond the Display Terminal}

The most widely accepted definition of usability is the ISO 9241 Part 11 standard [25], with its three dimensions of effectiveness, efficiency, and satisfaction. A strength of this standard is its emphasis on context and on the type of user and the type of task. ISO 9241-11 is clear that usability depends on the context of use, which includes the users in their specific circumstances.

However, reflecting its age, the standard is limited in its scope: usability is presented as a subset of ergonomics for office work with display terminals, although the document actually discusses usability beyond this narrow specification.

The definition of usability as detailed in ISO 9241-11 is too restrictive. This is partly in its narrow focus and outdated hardware context; the ways in which computers are encountered today include emergent interactive devices such RFID, mobile, and specialized interfaces, as well as Web interfaces. Nonelectronic interactions, as well as interactions between people, work alongside computers in experiences of computer use [22].

The ISO 9241-11 definition of usability is too restrictive, more fundamentally in its too-narrow conception of usability in [11]. ISO 9241-11 is concerned with the usability of a piece of equipment or software for a defined set of goals in office work. But goals are wider than this; it is not simply a question of being able to use, but of emotional reasons for wanting to use a system [11]. In the messy world outside the workplace, the goals of a user, their intentionality [12], will be framed in larger terms - getting to work on time, for example - which are not necessarily the same as the goals of the service provider.

\subsection{Encounters in Passing}

For service providers, systems and their related interactions are central to their work. For the service user, on the other hand, these interactions are peripheral. As computers are increasingly pervasive, accepted as ordinary tools for everyday life [4], so the focus of users is on the objects of their activities rather than on the computer artefacts themselves. From the point of view of service users, the interaction is merely a part of their daily routine: "In fact, users don't think of themselves as primarily having anything to do with the computer at all" [29].

These interactions are often semi-transparent [5]; the user presses the button or types on a keyboard without consideration for the action itself. Only when there is some problem does the equipment in itself become the focus of attention, an interruption in the flow of action, which Winograd and Flores [46] call a breakdown. This is action engaged with the world; its basis is tacit, pre-reflective knowledge; action is always carried out in a particular place and context.

\subsection{Meeting Users in the World}

The need for e-government to be capable of domestication [31] gives a new meaning to Nielsen's well-known heuristic: "match between the system and the real world" [36]. Beyond using words and conventions which are familiar to users, the interactions, no longer limited to what happens on a screen, must conform to users' expectations and fit with their daily routines. 
The analysis of affordances, popularised by Norman [37], has proven a powerful tool for HCI research and design. In meeting the needs of users, perceived affordances provide not only clues, but possibilities for action. As originally conceived by Gibson [15], affordances are essentially in the bodily relation between an actor and the environment; an animal perceives that a particular surface affords walking on, for example.

Software and computer interfaces also afford action [34]; the perception of affordances at an interface may be made available by a visual symbol whose interpretation may depend on some prior learning, but this does not deny the real possibilities for action in these virtual spaces. The user perceives that by performing a certain action, touching a smartcard against a card reader for example, a physical effect, such as opening a ticket gate, is achieved. Thus, perceiving the possibilities for action is important if a system is to be useful as well as usable.

\subsection{Interactions in Lived Experience}

The most frequent encounters with ICTs have - until recently been in workplaces. Once the computer leaves the desk, simplifications which rely on tacit assumptions about the users are no longer applicable: beyond the workplace, the user is not necessarily well-trained and may not have skills from long-term use. The user cannot be compelled to use the system in certain ways. Users outside the workplaces are heterogeneous, and encounter systems in situations which are varied, contingent, and unpredictable.

There is increasing awareness that human-computer interaction needs to be seen as part of the complex interplay between social actors and technology in many contexts and through various interfaces. Meeting the real world, computers are no longer only concerned with processing 'facts', but are used in diverse contexts which may be very different from those envisaged by the designers, and raise higher-order political and emotional issues [40].

These are the human needs of the lived experience [33] with technology. The lived experience goes beyond user experience with a computer to include many other technological and human objects, as well as the social user's own experience, capabilities, and values.

Lived experience emphasises the ways in which difficulties at the interface can lead to serious disruptions away from the interface in the lives of users. Thimbleby et al. [44] give an analysis of a ticket machine, in which poor interface design can have especially serious consequences. The extremely high volumes of use lead to important cost implications, as well as frustration and inconvenience for large numbers of passengers.

\section{UNDERSTANDING USERS' EXPERIENCES OF E-GOVERNMENT: THREE CASE STUDIES}

The increasing integration of computer power into mundane artefacts gives new significance to the question raised by Bannon and Bødker: how is it possible to understand an artefact which "reveals itself to us fully only in use?" [4]. How is it possible to grasp usability in the lived experience of socially situated users?

From a research tradition going back at least to Boland [6], this is a hermeneutic process, iteratively interpreting qualitative data from a close engagement with users. The aim is to understand not only what people do at the interface, but how this fits within their wider needs. This is a case study approach [47], drawing not only on discourse but on observation and analyses of the affordances $[15,34,37]$ of the systems, across cases which contrast in their uses of technology but are united by a single application area.

The cases studied here are all examples of electronicallyenabled services which go beyond putting existing services online, and indeed go beyond online in the sense of interaction through the Internet alone. All three of the implementations make use of Web interfaces; but in each of them, this is just one part of an ecology of interfaces and different media types [35, 39].

The studies consisted of interviews and focus groups with users of e-government services (120 participants in total), interviews with 25 staff in the government bodies and companies implementing the systems (at all levels including strategy and senior management), and observations of systems in use. The corpus also included over 80 documents on transport policy and its implementation. The case-specific data are detailed in the case study reports that follow; the total given here includes a number of staff interviews and documents relating to overall transport and e-government issues.

The average duration of interviews was approximately 40 minutes. Interviews and focus groups were voice-recorded, transcribed, and analysed using discourse analysis [38] and Grounded Theory [41]. This combination of analytical methods was suggested by the need to not only identify key causes and consequences in an inductive way, but to go beyond the findings of Grounded Theory to produce a rich, yet rigorous, reflexive analysis from different perspectives [1].

\subsection{Background to the Case Studies}

The findings are based on three case studies of systems in a single area of public policy, urban transport, implemented by a single authority, Transport for London (TfL). TfL, established in 2000 as part of the newly established Greater London Authority (GLA), has a remit covering all transport modes (currently with the significant exception of 'overground' Train Operating Company - TOC - services). The GLA, which includes a powerful mayor and an assembly, has overall responsibility for transport policy in London. Along with this devolution to a new, unified authority has come an integrated transport strategy, in which the implementations studied here, while diverse in their applications, support coherent overall policy objectives.

It is perhaps not immediately obvious that transport is a major area of public policy, and that information systems in support of transport policy can be categorized as e-government systems. But transport as an issue area touches on central public policy questions: the problems of urban traffic congestion and urban mass transport are high priorities for city government.

\subsection{The TfL Oystercard}

The TfL Oystercard is a transport smartcard for use in London. The card itself is an almost blank, blue, contactless RadioFrequency Identification (RFID) card which stores period tickets as well as Pay-as-you-go value which can be used to pay for individual fares 1 . Oyster is one of a number of similar implementations worldwide.

\footnotetext{
${ }^{1}$ Pay-as-you-go usually gives a discount over the equivalent cash fare. A daily 'cap' applies to such fares. This cap is guaranteed to be no more than the cost of the equivalent Day Travelcard, considering modes, zones, and off-peak travel.
} 
For TfL, the drivers behind the Oyster are to encourage public transport use through reducing barriers to access, to improve bus journey times by removing cash from bus boarding, and to free staff from the ticket office for other customer service activities.

\subsubsection{The Oystercard in Practice}

The Oystercard is touched onto touch-pads at ticket gates, on open DLR stations, and on board buses. Period tickets are checked, or, for Pay-as-you-go, the cost of the fare is deducted.

Value - either period tickets or Pay-as-you-go money value can be added at ticket machines, at some local shops, or by preordering online and then collecting (downloading) the value when passing through a ticket gate at a nominated station. Auto Top-up, introduced between September 2005 and June 2006, automatically adds a fixed amount whenever the value falls below £5. This avoids the recurring need to pre-order and to pass through a station (it works on buses as well), but requires pre-registration with TfL and still needs an initial pass through a nominated station to complete the configuration.

The TfL Oyster implementation centres on an artefact, the Oystercard; but this is only a part of the larger Prestige project to upgrade all London Underground and bus ticketing systems. In practical use, other artefacts - readers on ticket gates and machines, access to Oyster accounts online - are essential parts of the Oyster system as a whole.

\subsubsection{The Case Study}

For this study, 13 transport users took part in focus groups and 10 Oystercard users were interviewed individually. This research took place between January and December, 2004, thus covering several phases in the introduction of the card. Ten senior management staff and 3 representatives of transport advocacy groups were interviewed. An observation of the Oystercard in use at a very busy Underground station was also the opportunity for informal interviews with front-line staff. The written corpus included detailed analysis of relevant sections of the GLA Transport Strategy [16], explanatory leaflets, press reports, committee minutes, Web pages, and reports relating to areas of special interest: rail services and smartcards (a total of 25 documents).

\subsubsection{Experiences of Oyster in Use}

For TfL, the Oystercard provides revenue protection and new fare options, it enables cashless travel services, and possibly savings in the cost of sales. For a transport user, the Oystercard affords storage of Pay-as-you-go value or season tickets, it affords opening of ticket gates, and it affords use without removal from a wallet. However, unlike paper tickets, it does not afford visibility of the stored value without the mediation of some third device, such as a ticket machine at a station.

This presents problems for the user, since ticket machines are not always ready-to-hand; card-readers on buses and ticket gates provide additional visibility of the stored value, but these displays are small, and the time available to read them is very short.

Provided he or she trusts the system, an Oystercard user does need to track the value on their card; if using a period ticket, then, on expiry of the ticket, or if travelling beyond its zones, Pay-as-you-go value may be deducted automatically. However, this may conflict with the user's understanding of the system:

When I first used it, I don't really realise, I [went] to visit my friend, in High Barnet, which is like zone 5 and, "Oh, my God",
I don't really realise that it was charging me, ... so I went to customer service, I talked to them, and said, "oh, it's not working", and they said, "oh, you know you have, like, a limit, you haven't paid your prepay [Pay-as-you-go]". (Focus group member).

But in keeping track of the value of spending on fares, the blankness of the Oystercard contrasts with the embodiment of traditional tickets epitomised by single-use "Carnet" or "Bus Saver" tickets, where the link between a paper ticket and the fare value that it represents could not be more direct:

...the exact opposite of the, the way the Oyster card works with these, all these secret sort of amounts that go off or on you don't actually see, is the bus tickets with the little octagonal tabs that you tear off, you know exactly how many you've used, you know exactly how many you've got left, it's very, very simple. (Focus group member).

\subsubsection{Discussion}

Collection of fares is clearly an important part of transport service provision. Oyster therefore represents the intervention of electronic information systems into a traditional application area. As such, it is an example of the mundane, daily activities through which people encounter computers in their routine lives, usually in passing and peripherally to their central experience and volition.

The provision of unified ticket availability across all transport modes is particularly significant for transport integration, a stated transport priority [16]. It is all the more unfortunate that Oyster Pay-as-you-go is not available, for political and organisational reasons, on many TOC services; in London, many inner-suburban areas are served only by TOC lines. In addition to the inconvenience of the need for TOC users to buy one-off single tickets, this adds a layer of complexity to an already complex fare structure; it adds to a users' mental load, and reduces confidence in the system. ${ }^{2}$

\subsection{The Central London Congestion Charge}

The Central London Congestion Charge (CLCC) is a road charging scheme covering a single zone in central London. Charging is based on camera recording of number plates (Automatic Number Plate Recognition, ANPR) at entry and exit from the zone and while driving in the zone. As part of the integrated transport strategy, the CLCC is aimed primarily at reducing congestion, and at encouraging the use of forms of transport other than private vehicles.

\subsubsection{The CLCC in Practice}

Because the system does not work using electronic tags or other vehicle modification, vehicles entering the charging zone are recorded without any need for modification or pre-registration on the part of the driver.

It is only in payment of the charge that drivers interact directly with the CLCC system. The charge can be paid through a number of payment channels: at some local shops and petrol stations, online, by phone to a call centre, at machines in some car-parks, and, if pre-registered, by formatted SMS text message, or by post.

2 In January, 2007, the Association of Train Operating Companies accepted TfL's proposals to enable Pay-as-you-go by all London train operators [2]; some train services are already available for Pay-as-you-go, or soon will be. 
There are high penalties, initially $£ 80$ (reduced to $£ 40$ if paid within 2 weeks) for failure to pay the charge by the deadline ${ }^{3}$. As originally implemented and as in force at the time of this research, the charge had to be paid before midnight on the day of travel; if paid after $10: 00 \mathrm{pm}$, there was an additional $£ 5$ surcharge.

\subsubsection{The Case Study}

For this study, 50 CLCC payers were interviewed between midJanuary and mid-February 2005 using a structured interview, followed by 10 in-depth interviews from a mixed sample including drivers and non-drivers. There were also interviews with staff responsible for implementation, particularly for improving the customer experience, and with high-profile campaigners both for and against the CLCC, a total of 7 management and policy personnel.

The Road Charging Options for London report [18] and the relevant sections of the Greater London Authority Act 1999 [19] were analysed in depth, together with policy documents such as party manifestos, committee minutes and scrutiny reports, TfL and GLA press releases and other press comment, and impacts assessments (a total of over 30 documents).

\subsubsection{Experiences in Payment of the CLCC}

In the case of the CLCC, users are involved with conscious effort only in interactions in the process of payment. The process of payment, however, imposes on drivers the need to pay by the deadline, and to remember to pay. In this, it resembles the payment of transport fares, but, unlike fares, there are no physical barriers and no warning signs to act as reminders. Payment of the CLCC is peripheral to people's ordinary awareness; it is "not at the top of their mind":

...you get home at nine-thirty, you've got half an hour to pay it, but you come in .. I mean, sometimes people have been here, or something like that, you think, you know, you're not, it's not on top of my mind, really, ... but the worst one comes when you forget altogether, 'cos you've relaxed and had a glass of wine, or something (laugh), it's often happened, and then it's forty quid. (Individual interview).

It is perhaps unsurprising, given the consequences of failure to pay, that drivers are concerned to have tangible evidence of payment. Although payment of the CLCC is a licence in legal terms, no physical license is issued. Having heard reports from colleagues of payment problems during the early days of the CLCC, this payer has devised ways to ensure something slightly more concrete:

I always print out a copy of the receipt, just in case, and I email it to myself and make a note in my diary (laugh), well, because there were so many problems initially. (Individual interview).

For this charge-payer, electronic information does not feel sufficiently secure. As well as these subjective needs, there are sometimes practical needs for a proof of payment, for example in order to claim expenses. For such needs, the fluidity and uncertainty of information on the screen is insufficient; a printed copy, although originating in electronic data, provides greater certainty.

\footnotetext{
${ }^{3}$ Automated payment schemes exist for fleet vehicles, but not for private cars.
}

\subsubsection{Discussion}

The CLCC is the most high-profile of the implementations studied here, not only in terms of public awareness, but also as a political initiative which forms one of the main policies of the mayor of London. As such, it raised particular issues for usability; problems at this level could have led to political failure.

The charge was introduced in February 2003, that is, during the first term of office of the mayor of London, who had included a promise to introduce a congestion charge in his election manifesto and argued strongly for it. Timing of the implementation was therefore crucial; this was constrained not only by the political timetable, but also by the need to enhance public transport provision in readiness [3]. As a further consideration to make the CLCC more acceptable to the public, revenues for the scheme are used to fund public transport.

These balances and changes to details of policy are continuing. For example, when the charging zone was extended in February, 2007, as part of the discussion around the extension of the zone, the deadline for payment was extended to midnight on the day following the day of travel (this change was actually introduced in June, 2006) [17].

\subsection{The TfL Journey Planner}

The final study focuses on the TfL Journey Planner. This is similar to a number of other electronic journey planners in that it suggests preferred routes between a start and an end point, but it specifically gives journey information for multi-modal, sustainable or public transport in London. It is real-time, in the sense that it gives warnings of known current problems and takes the time of travel into account.

By providing information and route-planning on public transport, walking, and cycling, the TfL Planner (JP) aims to encourage use of sustainable modes of transport (public transport, walking, cycling) over unsustainable modes such as single-occupancy driving. It also aims to support socially inclusive empowerment of service users through accurate, clear, and real-time information. Real-time information could potentially give to public transport travel some of the flexibility of the private car, by enabling travellers to bypass disruptions or to reschedule travel plans dynamically [26].

\subsubsection{The TfL Journey Planner in Practice}

As considered by TfL, the JP across various channels is part of 6 key information touchpoints, which also include the TfL information call centre, staff at stations, and Travel Information Centres, and TfL Web, mobile, and interactive TV portals.

However, there are many other information resources available to London transport users, including written information in printed maps, leaflets, public displays at stations and bus-stops, personal knowledge, information from fellow travellers, and 'home-made' genres such as print-outs of street maps or handwritten notes.

The laboratory observations identified some detailed usability problems at the Web interface. Some of these were simple issues: difficulties locating the desired information, information off the bottom of the screen, information not what had been expected. More subtle problems were found in the quality of the suggested routes and in searching for a location; sometimes the participant could identify a better route, or very short bus trips were suggested, for example. 


\subsubsection{The Case Study}

For this study, in-depth interviews were conducted with 20 individual JP users, and focus groups with a total of 15 participants, between July and September, 2005. Data collection also included field observations of conventional and electronic sources of information in use. Documentary sources included business plans showing the importance TfL places on the JP, reports on customer information provision by transport organizations, and reports of the JP and other journey planners, a total of 10 documents. The study also included laboratory-based observations of a sample of 11 users performing scenario-based tasks; these observations were voice- and screen-recorded for later detailed analysis.

\subsubsection{Experiences in Urban Navigation with the JP}

The Journey Planner is an essentially mobile application, in the sense that travel information is potentially most useful when the user is away from home or desk [26]; it might be expected that mobile information channels would be widely used. However, the evidence from these interviews and observations refutes this expectation, at least at the current state of development of mobile information resources.

Analysis of in-depth interviews shows, rather, that transport users navigating the system make use of a constellation of unconsidered resources, working with the JP, forming an ecology of information; objects found serendipitously to hand provide information and resources for action. In the choice of these information sources, the physical properties of media come to the fore. Printed cycle maps, available free of charge from TfL, for example, were noted by several interviewees as convenient to carry even for non-cyclists, smaller and lighter than a standard street atlas. Conversely, printouts from the JP can run to several pages and are unwieldy; the JP has a section dedicated to cycle routes, but interviewees reported that these maps are too large to be useful while actually cycling.

A particularly cogent example of the failure of information resources to work together was mentioned in several focus groups. As a mode of transport, buses present special challenges to a traveller to learn the complex and frequentlychanging routes. Having identified a bus route using the JP, the passenger then has the problem of knowing when the destination has been reached. It is not always possible to see the name of the bus-stop from inside a bus, and, unlike in some other cities, buses in London do not indicate either visually or audibly the names of the upcoming bus-stops for the benefit of passengers. Thus, the JP information alone is insufficient; service users must find other sources of information, such as street signs, to complete their journey successfully.

This combining of different information resources as needed is also found at the central interface of the JP, the Web site. To overcome some of the shortcomings of the JP interface, observation participants were seen to make use of online maps to provide additional information in searches where the JP was unable to identify a route from the known data:

I never had this much fun. I used to put in a [postcode] and just get it and keep going. (Laboratory observation).

In this case, it is clear that this user is familiar with the JP but usually searches using personal knowledge, in this case the postcode; that is, personal knowledge is also an information resource, to be drawn on as necessary and in a way which the user would not normally remark on.

\subsubsection{Discussion}

Information from the JP centres on a Web site, but is also available over other channels: as a text message by sending a specially-formatted SMS message, at kiosks in stations and on the street, using PDAs with WiFi access, using WAP from a mobile phone.

However, it is in working together with other information resources that the JP it most useful. For users, there is not a clear distinction between the JP and other sources of information; these resources are electronic, traditional, or social as people ask friends or staff for advice, taking information as they find it and need it.

\section{RE-CONSIDERING USABILITY IN THE LIGHT OF USERS' EXPERIENCES}

It is now possible to apply the understanding of usability developed in Section 2 to the case studies described in the preceding section, to illuminate the ways in which these egovernment systems meet, or fail to meet, the needs of their users.

It is not simply that there are usability problems. A common thread running through the cases is the ways in which mundane contingencies of daily life combine with technological systems in the lived experiences of transport users. These form what have been called ecologies, human, social spaces alongside more or less sophisticated technologies as well as simpler artefacts [35].

But these grounded experiences of service users have implications for meeting policy aims, not only in the rationalistic, direct ways proposed by policy-makers, but in more complex ways, as the systems are interwoven into the positive or negative experiences of service users.

\subsection{Meeting the Users' Needs in Action}

Finding that an Oystercard has expired, being unsure as to whether a CLCC payment has succeeded, or not having a map to hand when travelling round London, are simple, almost trivial, everyday problems. However, in the experiences of service users, these apparently small problems can lead to a great deal of inconvenience and annoyance.

Rushing to a shop or a computer to pay the CLCC, or re-organising a journey in order to top-up an Oyster card, are deeply negative experiences, directly arising from a failure of design to take full account of users' real needs. Such negativity can lead to antagonism. In interviews, a number of people who were in general supportive of the CLCC recounted strongly negative experiences with payment, particularly around forgetting to pay; some who already held negative views of the CLCC had those views reinforced by these usability problems.

These usability shortcomings have their origins failures to match interactions to the context. The literature of ubiquitous computing is rich in considerations of context-aware computing; but, as Dourish [12] elaborates, context is not something separate from interaction, but rather context is a mutual achievement by parties to an interaction as part of their everyday, common-sense understandings of the social world.

To take another example from the studies, Section 3.2.3 showed the importance, for the user, of the knowing the value stored on an Oystercard. If an Oystercard affords gate-opening or busboarding, then all is well, but unexpectedly running out of value on the card could lead to the very physical experience of being refused entry to public transport. Overcoming this breakdown, 
to read the Oystercard or to download value to it, involves an ecology of artefacts, which must work together; but since ticket machines, card readers, and so on, are not readily available in many situations, this overcoming of the problem is only partial, and contingent on circumstances.

\subsection{Transparency and Abstraction}

Many of the interactions encountered in these studies - passing through a ticket barrier, glancing at a Tube map, driving past an ANPR camera while hardly being aware of it - are at the periphery of consciousness; they are transparent [24], hardly noticed by the transport user. This is how it should be; without this, there would be breakdowns in the smooth flow of action. However, breakdowns can also be positive; sometimes, examining the unconsidered flow beneficial, leading to new ways of seeing things.

Transparency in this sense is a form of abstraction, hiding from the user the underlying details of implementation. Abstraction is the fundamental way to manage complexity in information systems, "the very stuff of system design" [13]. Yet, as Dourish and Button also point out, abstraction can also lead to failures because "information hiding" may make important information unavailable to the user.

The Oyster system provides some clear examples of the contingent need to expose some of the underlying details of the system. The abilities of the information systems to mask the complexities of the transport system and to provide a seamless journey are compromised by real-world realities. The fares scheme is complex, and has some arcane exceptions; perhaps the most cogent example is the non-availability of Oyster Payas-you-go on some train services. To avoid running out of value, the user does have to be aware of some details of the fare structure and of a complex set of associated rules.

In a similar way, the TfL Journey Planner provides an abstracted view of the transport system, without which it would not be usable or useful. Yet users do need to push and prod [13] the system to obtain the information they need, and, in some cases, become skilled in doing so; an interviewee described searching for a route in two separate stages, having found that only in this way would it give the information that they wanted.

A strong finding from the interviews, which builds on some foundational HCI research [42], is the ability of users to understand and to overcome problems with the systems. Service users developed narratives to make sense of the system and are able to perceive and comprehend what Gaver [14] calls complex sequential affordances and hidden affordances. It is this working understanding which enables service users to overcome situations in which the systems fail to work together to match their everyday needs.

The point for policy-makers, and HCI designers advising them, is that interactions at the interface eventually lead to some realworld practices, in which details such as distance to the next bus-stop become immediately relevant. These details, directly observable in the physical world, are sometimes hard to link to their corresponding representation in the virtual JP world. Systems must make the resources available to users; failure to do so could have very non-virtual, practical consequences.

\subsection{Placing the Onus on the User}

Up to this point, this section has considered failures to meet the practical needs of transport users, and abstractions which mask necessary information from service users, and it has shown some of the strategies available to overcome these problems.
Underlying these issues, though, is a more fundamental question: many of these interactions place responsibility on the users to perform functions which might once have been performed by public servants. Enabled by e-government, the service user performs the interaction while public servants, if present at all, merely monitor and assist [21]. This is not only for economic reasons, but might also be preferred by a user, being perhaps faster or more convenient.

However, passing responsibility down to the user is also a usability issue; in Nielsen's terms, placing this onus onto users adds to their memory load [36]. The user has to grasp the need to perform the interaction, often without any prompting contrary to Nielsen's 'recognition rather than recall' heuristic.

For example, in addition to the need to ensure that they are in possession of a current ticket, common to traditional tickets as well, the user of an Oystercard also has to ensure that they "touch in and touch out" against the card reader at the start and end of every journey. As from November, 2006, failure to do so results in a higher fare being deducted from Pay-as-you-go users. Thus, where once a transport user would have paid cash in exchange for a simple ticket, now there is an additional responsibility to ensure that the fare is paid 'correctly'. Thus, although abstraction masks the need to calculate the correct fare, a new and different responsibility is placed on the user to ensure that the collection is completed, in circumstances in which this is not always easy.

This 'downloading' of responsibility is even clearer in the case of the CLCC, in which the licence and enforcement model places on the charge-payer the risk of incurring a large Penalty Charge. In response, in the practices discussed in Section 3.3.3, charge-payers are anxious to avoid payment problems, for example, by printing out electronic receipts.

In the case of the CLCC, it is possible to envisage systems which could, conversely, make use of technology to alleviate some of the responsibility from the user; some trials of location identification technologies and of 'tag and beacon' have been undertaken by TfL [43]. However, even if such a scheme were to be used, not all vehicles entering the zone would be fitted with the necessary on-board units or other equipment.

Perhaps suggesting a counterbalance to this general impetus, Oyster offers an example of the use of technology to remove some of the responsibility from the user, even while adding new responsibilities in the form of the need to "touch in and touch out", since the Auto Top-up system removes the need for a user to remember to add value to their card - once they have registered it. This is only a partial solution, since this implies a new need to trust TfL to calculate and deduct fares correctly.

\subsection{Analysis: Technology in Support of Policy Aims}

The basic premise which opened this paper is that e-government is implemented with the aim of supporting public policy outcomes in various ways. Each of the implementations described in this paper is broadly in support of a rather simple policy aim: to encourage the use of sustainable modes of urban transport, and discourage the use of the private car.

Section 1 suggested some at a theoretical level some ways in which policy might be supported or threatened by good or poor usability. The findings in Section 3 and the analysis in the subsections above give concreteness to the theory, in the positive or negative experiences of service users. 
The continuing response by e-government service providers, for example in the extension to the CLCC payment deadline, suggests that there is a concern for usability by policy-makers, but a lack of understanding that implementation cannot be separated from the fundamental design of policy. This reflects a systems rationalism which considers the embodied experiences of service users to be peripheral; in contrast, the view taken in this paper places experience in use of the systems at the centre and, therefore, brings it into all stages of policy-making.

So, for example, the Oystercard is not simply an implementation of a policy to upgrade ticketing systems and to make public transport more attractive, but is part of the policy. The feelings of uncertainty around the need for users to "touch in and touch out", mis-understandings about some of the charges made, the "secret sort of amounts that go off or on" the card, and the need to trust the correct calculation of fares, are inseparable from the larger policy. The uncertainty is compounded by the lack of visibility of the stored value and the practical difficulties arising from breakdowns in the ecology, for example the need to download value at a pre-nominated station.

In the JP, the challenge is rather different: policy objectives may fail if they are based on a rationalist assumption that plans for sustainable travel will in some way of themselves encourage the use of sustainable transport modes. The study found that the JP is used as just one of many information resources, and in ways which do not conform to a simple planning model.

For policy-makers aiming to encourage the use of sustainable transport, the lesson is that, rather than concentrating on the JP alone to provide travel plans, it is more appropriate to ensure that navigational resources are coherent, thorough, accurate, and timely, and work together with other information resources to support navigation.

\section{USABILITY IN POLICY DESIGN}

E-government provides a privileged position from which to observe usability in the mundane practices of heterogeneous users. E-Government may provide useful services for the citizen, in which interaction flows smoothly, peripheral to the users' main concerns. On the other hand, citizens may be obliged to interact with services to undertake a legal duty, such as renewing a licence or paying a charge, which for most people are not so much a service as a nuisance [30].

Usability is a fundamental in both of these types of interaction, whether to enable pre-reflective, spontaneous performance of routine actions, or to reduce as far as possible the inconvenience of citizens' obligations. Yet policy-makers have not often considered their analyses in HCI terms, and conversely, HCI practitioners do not in general consider the implications of their work for public policy.

Underlying much e-government policy is an implicit assumption that it is sufficient for services to be provided in ways which are more cost-effective, information more readily available and more timely, and access to services faster and easier. For reasons outlined in Section 1, this ignores the essential usability of services, and the lived experiences with those services. It is in a thorough understanding of everyday details, and of what Suchman [42] calls the somehow which links daily practice to the ability make use of the systems, and links the use and usefulness of systems to public policy goals, that HCI can make its strongest contribution.

\subsection{Tensions Between Policy and Practice}

A traditional approach to public policy-making would envisage professional analysts proposing rational strategies to achieve political objectives set by decision-makers [3].

This traditional view is challenged both by political realities and experience in practice. On the level of interaction, what actually happens locally in mundane encounters is local, intimate, and flexible [40]; on the other hand, public policies, providing baseline standards and continuity, are global and large-scale. Policies made in debate and in policy documents are experienced and interpreted locally. Local breakdowns, perhaps unconsidered or hard to see at the design level, are immediately perceived by service users; the larger breakdown, harder to see and to deal with, might be a lack of co-ordination between service providers and the policy level.

One of the mayor of London's statements on changes to the charging scheme shows the balancing of differing realities particularly clearly [17]. The extension of the payment deadline, on the recommendation of TfL, is an implicit acknowledgement that paying within the day does not necessarily "match the real world" [36]. But, as outlined in practical terms in Section 3.3.4, this change was not made as a one-off revision to the scheme, but as part of same variation order that extended the charging zone into west London; that is, as part of a package of political decisions, carefully balanced to be acceptable to a range of stakeholders.

\subsection{Towards Usable e-Government}

However, timescale, cost, and other competing pressures, as well as the scale of implementation, are constraints on policy and its implementation. Meanwhile, various strategies are applied to manage usability shortcomings: phased introduction of services, using the authority of government to oblige the use of particular services, or providing a choice of channels.

Each of these strategies is problematic. Phased introduction may allow for post-implementation changes to overcome usability issues, but, whilst a continuing, dialogical development of systems is welcome, it would be preferable to prevent usability problems prior to implementation.

A variety of channels is an appropriate way of addressing the different situations in which services may be encountered, but choice alone does not overcome fundamental problems if the choice is among channels each of which is unsatisfactory. The analysis of the ways in which systems sometimes fail to meet users' needs (Section 4.1) demonstrates that, in everyday situations, often no single channel can provide adequate, usable support for the desired action.

What is needed is systematic analysis of usability concerns at all stages, from the start of the design of public policy. This leads to a didactic message, familiar to HCI research [7] but often neglected in public policy: usability design must be incorporated in, not added on to, systems design at all stages; it cannot be left to implementation.

\section{THE WAY FORWARD}

How can policy-makers actualise this need? Drawing on the findings of these case studies, this paper makes its final contribution with some suggestions of practical ways in which this might be done in public policy design.

Designers can start by developing an involved understanding of the situatedness [42] of interactions. More than the context of use, interacting with systems is a continual process of making 
sense of them and of their possibilities for action, in order to achieve practical goals.

These are the goals of the users, rather than those of the service provider. E-Government is implemented to support policy aims; these are the 'drivers' of the systems, built into strategy documents and business plans. But the goals of the users are in their lived experiences, in their personal desires and practical needs; the systems as such are of little interest to them. Cooper [8] makes clear the distinction between goals and tasks; design should be at the level of goals, rather than tasks. For a user, payment of the CLCC is not a goal, but is rightly called a task; their goal is to drive in central London, and this, in turn, is part of whatever larger goal requires them to drive.

The sometimes antagonistic responses of users to local breakdowns reflect the tension between users' goals and those of policy-makers, and between policy and its realisation. Local breakdowns are immediately apparent to users, but this immediacy and familiarity offers a potentially useful resource for policy-makers and designers. If there is resistance or antagonism on the part of the user, citizen or customer, the point is not to 'solve' the resistance, but to use it as a clue to what went wrong and for suggestions for improvement [32]. Involving the users at the earliest stages makes such local breakdowns visible to designers, overcoming mis-matches between systems and the world of users.

Thinking about 'the user' as an ill-defined 'factor' is to ignore the users as real, varied human beings, with needs and desires. McCarthy and Wright [33] have developed a profound understanding that, as technology is more and more involved in daily life, so computer power is not simply used, but lived with. Designing technology and living with it are both emotional and aesthetic experiences; bringing users into design overcomes the separation of design and use, restoring continuity between design and lived experience [33].

This paper has been concerned to emphasise that the physical, situated world is not something separate from abstract reason, but that both design and use occur in interaction with the concrete world. Seen in this way, the material properties of artefacts provide affordances, or resources, for social action. This suggests that designers should be asking: in what ways does the new ecology of affordances support the policy, and what is lost between the old and the new? For example, unconsidered features of a simple payment system, the tangibility of a paper slip, or the personal knowledge of a regular customer, are all part of the ecology of the system.

The systems studied in this paper show numerous examples of policy-makers responding to usability problems following resistance or negative responses from the public. While these improvements may be seen as positive to the extent that they reflect dialogue between service users and politicians, this does not overcome already negative experiences of users resulting from a failure to recognise the need for usability to be part of the design of the system prior to implementation.

\section{REFERENCES}

[1] Alvesson, M., and Sköldberg, K. Reflexive Methodology: New Vistas for Qualitative Research. Sage, London, UK, 2000.

[2] Association of Train Operating Companies. ATOC's Position on Oyster Pay-as-you-go and the Offer by Transport for London. Press Release, January, 2007. At http://www.atoc-comms.org/dynamic/atocpressstory.php?atoc $=997793$, Last retrieved: 06/06/2007.
[3] Banister, D. Critical pragmatism and congestion charging in London. International Social Science Journal, 55, 2 (2003), 249-264.

[4] Bannon, L. J., and Bødker, S. Beyond the interface: Encountering artifacts in use. In J. M. Carroll (ed.), Designing interaction: Psychology at the human-computer interface. Cambridge University Press, Cambridge, UK, 1991, 227-253.

[5] Bødker, S. Through the Interface: A Human Activity Approach to User Interface Design. Lawrence Erlbaum Associates, Hillsdale, NJ, 1991.

[6] Boland, R. J. J. Information systems use as a hermeneutic process. In Proceedings of IFIP TC 8 WG8.2. (Copenhagen, Denmark, 1990). 1990, 439-458.

[7] Chrusch, M. Seven great myths of usability. Interactions, (September \& October, 2000), 13-16.

[8] Cooper, A. The Inmates are Running the Asylum: Why High-Tech Products Drive Us Crazy and How to Restore the Sanity. SAMS, Indianapolis, IN, 1999.

[9] Deci, E. L., and Ryan, R. M. The support of autonomy and the control of behavior. Journal of Personality and Social Psychology, 53, 6 (1987), 1024-37.

[10] Dillon, A. Group dynamics meet cognition: Combining socio-technical concepts and usability engineering in the design of information systems. In E. Coakes, D. Willis, and R. Lloyd-Jones (eds.), The new SocioTech: Graffition the long wall. Springer-Verlag, London, 2000, 119-125.

[11] Dillon, A. Beyond Usability: Process, Outcome, and Affect in Human Computer Interactions. Paper presented as the Lazerow Lecture at the Faculty of Information Studies, University of Toronto, 2001.

[12] Dourish, P. Where the Action Is: The Foundations of Embodied Interaction. MIT Press, Cambridge, MA, 2001.

[13] Dourish, P., and Button, G. On 'technomethodology': Foundational relationships between ethnomethodology and system design. Human-Computer Interaction, 13, 4, (1998), 395-432.

[14] Gaver, W. W. Technology affordances. In Proceedings of the SIGCHI conference on Human factors in computing systems (CHI 1991). ACM Press, New York, NY, 1991, 79-84.

[15] Gibson, J. J. The Ecological Approach to Visual Perception. Houghton Mifflin Company, Boston, MA, 1979.

[16] GLA. The Mayor's Transport Strategy: Executive summary. GLA, 2001. At http://www.london.gov.uk/mayor/strategies/transport/ pdf/final_execsumm.pdf, Last retrieved: 06/06/2007.

[17] GLA. Statement by the Mayor Concerning his Decision to Confirm the Variation Order for the Western Extension of the Central London Congestion Charging Zone with Modifications. GLA, 2005. At http://www.london.gov.uk/mayor/congest/docs/mayorstatement-092005.pdf, Last retrieved: 06/06/2007.

[18] Government Office for London. The Road Charging Options for London (ROCOL) Report. GOL, 2000. At http://www.gos.gov.uk/gol/transport/ 161558/228862/228869/, Last retrieved: 06/06/2007.

[19] Greater London Authority Act, 1999: Schedule 23: Road User Charging.

[20] Grimsley, M., and Meehan, A. e-Government information systems: Evaluation-led design for public value and 
client trust. Electronic Journal of Information Systems, 16, 2 (2007), 134-148.

[21] Grönlund, A. E-democracy and e-government: State of the art. In Proceedings of 68th IFLA Council and General Conference (Glasgow, UK, 2002). 2002.

[22] Grudin, J., Interface: An evolving concept. Communications of the ACM, 36, 4 (1993), 110-119.

[23] Hood, C. C. The Tools of Government (First American Edition). Chatham House Publishers, Chatham, NJ, 1983.

[24] Ihde, D. Technics and Praxis. D. Reidel Publishing Company, Dordrecht, Netherlands, 1979.

[25] ISO 9241-11 Ergonomic Requirements for Office Work with Visual Display Terminals (VDTs), Part 11: Guidance on Usability. International Organization for Standardization, 1998.

[26] Jain, J. Bypassing and WAPing: Reconfiguring timetables for 'real-time' mobility. In M. Sheller, and J. Urry (eds.), Mobile technologies of the city. Routledge, Abingdon, UK, 2006, 79-101.

[27] Kapor, M. A software design manifesto. In T. Winograd (ed.), Bringing design to software. Addison-Wesley Professional, Reading, MA, 1996.

[28] Kelly, G., Mulgan, G., and Muers, S. Creating Public Value: An Analytic Framework for Public Service Reform. Strategy Unit Discussion Paper, Cabinet Office, London, UK, 2002. At http://www.cabinetoffice.gov.uk/strategy/downloads/files/ public_value2.pdf, Last retrieved: 06/06/2007.

[29] Lamb, R., and Kling, R. Reconceptualising users as social actors in information systems research. MIS Quarterly, 27, 2 (2003), 197-235.

[30] Lenk, K., and Traunmüller, R. Electronic government: Where are we heading? In Proceedings of Electronic government: First international conference (EGOV 2002). (Aix-en-Provence, France, 2002). 2002.

[31] Margetts, H., and Dunleavy, P. Cultural Barriers to eGovernment: Better Public Services through eGovernment. Academic Article in support of Better Public Services through e-government, NAO, 2002. At http://www.governmentontheweb.org/downloads/papers/ Cultural_Barriers.pdf, Last retrieved: 06/06/2007

[32] Markus, M. L. Power, politics, and MIS implementation. Communications of the ACM, 26, 6 (1983), 430-444.

[33] McCarthy, J., and Wright, P. C. Technology as Experience. MIT Press, Cambridge, MA, 2004.
[34] McGrenere, J., and Ho, W. Affordances: Clarifying and evolving a concept. In Proceedings of Graphics Interface 2000. (Montréal, Québec, Canada, 2000). 2000, 179-186.

[35] Nardi, B. A., and O'Day, V. L. Information Ecologies: Using Technology with Heart. MIT Press, Cambridge, MA, 1999.

[36] Nielsen, J. Ten Usability Heuristics. Useit.com, 2005. At $\mathrm{http}: / /$ www.useit.com/papers/heuristic/heuristic_list.html, Last retrieved: 06/06/2007

[37] Norman, D. A. The Design of Everyday Things. Basic Books, New York, NY, 1988.

[38] Potter, J., and Wetherell, M. Discourse and Social Psychology: Beyond Attitudes and Behaviour. Sage, London, UK, 1987.

[39] Spinuzzi, C. I. Describing Assemblages: Genre Sets, Systems, Repertoires, and Ecologies. Computer Writing and Research Lab White Paper, University of Texas, Austin, TX, 2004. At http://www.cwrl.utexas.edu/files/040505-2.pdf, Last retrieved: 06/06/2007

[40] Star, S. L., and Ruhleder, K. Steps toward an ecology infrastructure: Design and access for large information spaces. Information Systems Research, 7, 1 (1996), 111134.

[41] Strauss, A. L., and Corbin, J. M. Basics of Qualitative Research: Techniques and Procedures for Developing Grounded Theory. Sage, London, UK, 1998.

[42] Suchman, L. A. Plans and Situated Actions: The Problem of Human-Machine Communication. Cambridge University Press, Cambridge, UK, 1987.

[43] TfL. London Congestion Charging Technology Trials: Stage 1 Report: February 2005, at http://www.tfl.gov.uk/assets/downloads/technologytrials.pdf, Last retrieved: 06/06/2007

[44] Thimbleby, H., Blandford, A., Cairns, P., Curzon, P., and Jones, M. User interface design as systems design. In People and Computers XVI (Proceedings of HCI 2002). Springer, London, UK, 2002, 281-301.

[45] Weiser, M. The computer for the 21 st Century. Scientific American, 265, 3 (1991), 66-75.

[46] Winograd, T., and Flores, F. Understanding Computers and Cognition: A New Foundation for Design. Ablex, Norwood, NJ, 1986.

[47] Yin, R. K. Case Study Research: Design and Methods (Second Edition). Sage, London, UK, 1994. 